\title{
Correction to: Storm Event Nitrogen Dynamics in Waterfowl Impoundments
}

\author{
B. R. Hinckley • J. R. Etheridge • A. L. Peralta
}

Published online: 2 May 2020

C) Springer Nature Switzerland AG 2020

Correction to: Water Air Soil Pollut (2019) 230:294

https://doi.org/10.1007/s11270-019-4332-5

The original version of this article unfortunately contained an error in the areas of the impoundments reported in Section 2.1 of the published article. The corrected sentence is shown below.

Two waterfowl impoundments in Hyde County, North Carolina, USA, a 42.9-ha agricultural field (Ag; Fig. 1a) and a 117-ha moist-soil managed (MSM; Fig. 1b) impoundment, were monitored from July 2016 through January 2018.

The online version of the original article can be found at https://doi.org/10.1007/s11270-019-4332-5

B. R. Hinckley · A. L. Peralta

Department of Biology, East Carolina University, Greenville, NC 27858, USA

J. R. Etheridge

Department of Engineering, East Carolina University, Greenville, NC 27858, USA

J. R. Etheridge $(\bowtie)$

Center for Sustainable Energy and Environmental Engineering, East Carolina University, Greenville, NC 27858, USA

e-mail: etheridgej15@ecu.edu

Present Address:

B. R. Hinckley

Department of Marine, Earth, and Atmospheric Sciences, North Carolina State University, Raleigh, NC 27607, USA 